\section{Earth Tides and Ocean Tides.}

IN some respects notable progress has been made in the problem of the earth tides since $r 862$, when Lord Kelvin directed attention to the difference between the observed amplitudes of the fortnightly oceanic tides and their theoretical amplitudes on a perfectly rigid earth and based on this fact an estimate of the earth's modulus of rigidity. On the instrumental side, the interferometer apparatus of Michelson and Gale ${ }^{\prime}$ represents a notable advance over the horizontal pendulum. On the theoretical side, the investigations of Herglotz, Schweydar, Love and Hoskins ${ }^{2}$ have enabled us to deal with an earth which so far as the physical properties of its interior are concerned, resembles the actual earth much more closely than does the homogeneous, incompressible sphere with uniform rigidity throughout treated by Lord Kelvin.

In one part of the problem, however, almost no advance has been made. The observed tidal oscillations of the earth are considerably affected by oceanic tidal oscillations of identical periods, but not, in the long run, by oscillations of different periods. When observations with horizontal pendulums made some years ago in various places near the Baltic Sea indicated a greater apparent rigidity in the prime vertical than in the meridian, and when various ingenious explanations of this peculiarity were found to be untenable, it came finally to be accepted that the true explanation lay in the effect of the oceanic tides. A little calculation shows that the effect of the varying load of tidal water may extend to distances that, at first thought, might seem surprising.

The difficulty of correcting for the oceanic tide is twofold; first the complicated calculations necessary, and second the lack of observational data on the amplitudes and phases of the tides in the open sea. As to the first, however, the method of Boussinesq, which reduces the calculation of the yielding under a surface pressure to the calculation of a certain gravitational potential, is easily applied and has been used by Japanese investigators ${ }^{3}$ in connexion with earth tides with fair success, in spite of the fact that the conditions postulated in Boussinesq's solution are somewhat remote from those of Nature. Doubtless more satisfactory methods of calculation would be devised, if only the essential data of observation, namely the facts about the tides at sea, were available.

For tidal oscillations (or, for short, simply tides) of long period, theory may, to a large extent, take the place of observation, since it seems very probable that these long-period tides conform rather closely to the equilibrium theory, a statement which cannot be made of the short-period tides, diurnal or semi-diurnal. The smaller amplitudes of the long-period earth tides in comparison with those of short period, and the consequent loss in relative accuracy with which the former can be observed, maybe more than compensated by the greater accuracy with which the long-period tides may be corrected for the effects of the corresponding oceanic tides.

One purpose of this communication is therefore to urge that greater attention be paid to long-period

\footnotetext{
1 Astrophysical Journal, Vol. 50 (I9I9), p. 330.

2 G. Herglotz: "Über die Elastizität der Erde bei Berücksichtigung ihrer variablen Dichte," Zeitschrift für Mathematik, Vol. 52 (1905), p. 275.

W. Schweydar: "Theorie der Deformation der Erde durch Flutkräfte," Veröffentlichung des Königlich Preuszischen Geodätischen Institutes, neue Folge, No. 66, I9r6.

A. E. H. Love: "Some Problems of Geodynamics," chaps, iv.-viii, xgrr.

L. M. Hoskins: "The Strain of a Gravitating Sphere of Variable Density and Elasticity," Transactions American Mathematical Society, Vol. 2 I (I920), p. I.

(I920), P. I. Shida: Memoirs of the College of Science and Engineering, Kyoto Imperial University, Vol. 4, No. r, Igr2.

R. Sekiguchi : "Tidal Earth Tilting," Memoirs, Imperial Marine Observatory, Kobe, Japan, Vol. I (rg22), p. x.
}

NO. 285 I, VOL. I I 3$]$ tides both of the solid earth and of the ocean. In spite of their scientific importance long-period tides have been rather neglected in comparison with shortperiod ones, which are larger and of more immediate concern to the navigator. A publication of the U.S. Coast and Geodetic Survey now in press lists 820 tidal stations in all parts of the world at which harmonic tidal constants have been computed, but at orily I39 of these were the constants for the fortnightly and monthly tides derived. For the observation of these tides European scientific workers are geographically better situated than those of the United States. The long-period oceanic tides vanish in latitude $35^{\circ}$ and reach maximum amplitudes at the equator and at the poles, the polar amplitude being twice the equatorial. In latitude $55^{\circ}$ the amplitude is as great as at the equator. In this latitude, or in even higher latitudes, it would be practicable to make good tidal observations in Europe, but scarcely practicable in North America. For the earth tides, the geographical advantage of Europe over North America is somewhat less, since the long-period earth tides, being measured by the deflexion of the vertical, and not by the height of the disturbed level surface as compared with the undisturbed, attain their maximum amplitudes in latitude $45^{\circ}$.

It is desirable in the study of long-period tides to obtain information not merely about the elastic properties of the earth conceived as a perfectly elastic solid, but also about the departures of the earth from perfect elasticity, a matter of which very little is known. For this latter purpose the longer the period of the tide studied the better. Consequently a study of the tides connected with the eighteen-year revolution of the moon's node would be very desirable.

Another purpose of this communication is to ask for information about recent work on earth tides, whether experimental or theoretical, already accomplished or projected. The writer has been designated rapporteur on earth tides to the section of Geodesy, International Geodetic and Geophysical Union; it is therefore his duty to prepare a report on the subject for the coming meeting of the Union at Madrid. $\mathrm{He}$ has tried to reach directly persons likely to be interested in earth tides, but in view of the present difficulty in getting scientific articles printed at all, and the apparently opposite but very real difficulty due to the multiplicity of organs of publication, it is very probable that he has failed to reach many who are in a position to give him valuable information. The writer would, therefore, be glad to receive information of this sort, reprints of memoirs, etc., and hopes that readers of this communication will not construe the words " earth tide" too narrowly, but will include in them all related matters pertaining to the yielding of the earth to applied forces.

\section{U.S. Coast and Geodetic Survey, \\ Department of Commerce, Washington, D.C., U.S.A., May 7. \\ Relation between Pressure Shift, Temperature Class, and Spectral Terms of the Iron Lines.}

IT has been long recognised that the lines of the iron spectrum are displaced towards the red when the pressure about their source is increased, the magnitude of the displacement being not the same for all the lines. On account of this fact Gale and Adams (Astrophys. Journ. 35, I912, p. Io) have classified the lines in four groups, $a, b, c$, and $d$. Group $a$ includes all the flame lines, which have small displacements.

4 Paul Schureman: "A Manual of the Harmonic Analysis and Prediction of Tides," Special Publication, No. 98. 